\title{
ИНСТИТУЦИОНАЛЬНЫЕ УСЛОВИЯ И МЕХАНИЗМЫ СГЛАЖИВАНИЯ СОЦИАЛЬНОГО НЕРАВЕНСТВА ПОТРЕБИТЕЛЕЙ МЕДИЦИНСКОЙ ПОМОЩИ В РОССИЙСКОМ ОБЩЕСТВЕ
}

\author{
Вялых Никита Андреевич, \\ sociology4.1@yandex.ru
}

\begin{abstract}
Институт социологии и регионоведения Южного федерального университета, Россия, 344006, г. Ростов-на-Дону, ул. Пушкинская, 160.
\end{abstract}

Вялых Никита Андреевич, кандидат социологических наук, доцент кафедры теоретической социологии и методологии региональных исследований Института социологии и регионоведения Южного федерального университета.

В статье рассматриваются практические подходы к снижению степени дифференциации потребления медицинской помощи в современном российском обществе. Актуальность исследования продиктована необходимостью создания доступного и эффективного пространства здравоохранения в России. Новизна работы заключается в определении противоречия между явными функциями и реальными интересами различных агентов в системе здравоохранения. Особое внимание уделяется последствиям сокращения государственного участия в сфере здравоохранения. Доказывается, что в основном интересы государства и потребителей в сфере медицинского обеспечения сходятся. Однако общество до сих пор ожидает поддержки и заботы со стороны государства, а государство постепенно снижает степень своего участия. Автором выделены теоретические и методологические предпосылки социологического понимания социальных различий в сфере потребления медицинской помощи, а также определен комплекс мер позитивизации поведенческих стратегий акторов в контексте трансформации института здравоохранения в современной России. Сәлаживание дифференциации потребления медицинской помощи зависит от функционирования регулирующего, интериоризирующего и воспроизводящего институциональных механизмов. Показано, что институциональный механизм - это система согласования и упорядочения интересов различных агентов посредством разработки и установления формальных и неформальных социальных норм в сфере здравоохранения с их последующей интериоризацией и социальным воспроизводством. Особое внимание уделяется анализу поведенческих и структурных измерений неравенства в доступности медицинской помощи. Обосновывается идея о том, что усиление государственного контроля - необходимая мера в сфере медицинского обеспечения, но стимулы к модернизации здравоохранения в бюджетностраховой модели крайне слабы. Автор приходит к выводу о возможности сглаживания социального неравенства потребителей медицинской помощи посредством конкретизации гарантий бесплатной медицинской помощи и ответственности агентов, сокращения непосредственных платежей пациентов, интеграции процесса лечения, социального диалога и инфосоциализации агентов.

Ключевые слова: Социальная дифференциация, потребление медицинской помощи, доступность медицинской помощи, российское здравоохранение, агенты, трансформация, институциональные механизмы.

Медико-социальные, ментальные, социокультурные и институциональные проблемы формирования и воспроизводства практик медицинской активности - это мейнстрим современной социологической мысли. Отдельного рассмотрения заслуживают несправедливые различия в сфере потребления медицинской помощи и способы их нивелирования. В социологической перспективе справедливость - это социально реля- 
тивные представления общества и человека о должном порядке вещей в какой-либо сфере жизнедеятельности. В социологии здравоохранения предметом социологических исследований, как правило, становятся несправедливые социальные различия, при которых представители разных социальных страт имеют неодинаковые шансы на получение медицинской помощи. К примеру, если пол, возраст, территория проживания, уровень дохода, род деятельности и другие социально-статусные параметры существенно снижают доступность медицинской помощи для определенных социальных групп населения, то мы можем говорить о несправедливых различиях [1].

По оценкам представителей Федерального научно-исследовательского социологического центра Российской академии наук, лидерами в списке основных направлений перемен, которых ждут от государства россияне, являются: усиление социальной справедливости, борьба с коррупцией, преодоление нефтегазовой зависимости экономики России, а также развитие науки, образования, здравоохранения и культуры [2]. В социальных представлениях россиян неравенство в доступе к медицинской помощи - самый болезненный для общества и личности вид неравенства, а болезни, инвалидность - вторая после алкоголизма и наркомании причина бедности [3]. Но далеко не все социальные неравенства в сфере здравоохранения можно определить как несправедливые, т. к. доступ к медицинской помощи зависит не только от факта наличия/отсутствия объективных возможностей для удовлетворения медицинских потребностей населения, но и не в меньшей степени от сознательной активности отдельно взятого человека. Например, если при одинаковой конфигурации экономического и социального капиталов (дохода, связей, знакомств, среды обитания) один из двух пациентов обладает большим культурным и символическим капиталом (осведомленность о деятельности регионального здравоохранения, информационная и правовая грамотность, знание медицинских терминов, понимание статуса своего здоровья и т. п.) и в силу этого достигает быстрее и менее затратно по ресурсам своей цели (получение адекватной медицинской помощи), то едва ли можно говорить о том, что такое различие оказалось несправедливым [4]. По мнению М. Пулока, справедливость в здравоохранении достигается тогда, когда потребность определяет распределение и использование медицинских услуг независимо от таких параметров как доход, регион, образование, профессия и др. [5].

О методологических установках и теоретических традициях социологического исследования неравенства потребителей медицинской помощи подробно изложено на страницах «Вестника науки Сибири» в 2018 г. [6], поэтому в данной статье внимание уделено анализу существующих факторов воспроизводства социального неравенства потребителей в пространстве института здравоохранения в современном российском обществе и научному поиску институциональных механизмов-антагонистов процесса дифференциации в этой сфере.

Есть ряд причин, актуализирующих значение социологического изучения социальных различий потребителей медицинской помощи. Они весьма характерны именно для российского общества. Основная из них - продолжающиеся реформы в системе здравоохранения и связанная с ними необходимость пересмотра политики и роли государства, а также других системообразующих социальных институтов, прежде всего семьи, религии, образования, здравоохранения и средств массовой коммуникации в этом процессе. Стремительное старение российского населения и повышение планки пенсионного возраста ставят перед государством важную задачу - обеспечить благоприятные условия для сохранения и укрепления общественного здоровья. Не менее важный аргумент в пользу актуальности - значимость ревизии и модернизации существующих методологических подходов и методик диагностики доступности услуг здравоохранения как социального института. Прибавим сюда парадоксы и противоречия формирования 
культуры здоровья и культуры болезни, которые детерминируются не столько контекстуальными, сколько поведенческими факторами. В связи с этим социологический анализ представлений различных социальных групп общества о здоровье и болезни, определение специфики социального поведения в сфере здравоохранения, индикация здоровьесберегающих и здоровьеразрушающих повседневных практик представляются особенно своевременными и практически необходимыми задачами для науки и институтов социального управления общественным здоровьем.

Опыт социальной экспертизы и диагностики проблем, существующих в системе российского здравоохранения, показывает, что лишь незначительная доля предложений и рекомендаций внедряется лицами, принимающими управленческие решения. Но это не означает, что социально-гуманитарные и медико-социальные исследования в области здравоохранения лишены смысла. По крайней мере руководители от здравоохранения располагают вариантами решения различных проблем и понимают, как эксперты и научное сообщество оценивают варианты принятия специальных мер по улучшению здоровья тех, кто находится в экономически и социально неблагоприятном положении. Отсутствие ясности в отношении концепций дифференциации потребителей в сфере здравоохранения может иметь серьезные последствия на стадии распределения ресурсов, поскольку социальная справедливость нередко исключается из программ социального развития общества [7].

Проблемное поле формирования равнодоступности медицинской помощи обнаруживается в противоречии между институциональной средой, которая лимитирует способности и возможности человека удовлетворять свои потребности в физическом, психическом, социальном и духовном здоровье, и ментальными программами, детерминирующими практики здравоохранительной активности. Для разрешения этого противоречия необходимо разрабатывать структурно и личностно ориентированные социальные технологии, обеспечивающие устойчивое развитие института здравоохранения. Отдельные аспекты функционирования здравоохранения и управления здоровьем в современном российском обществе являются предметом множества научно-исследовательских практик, в том числе междисциплинарных, однако проблематика дефиниции институциональных механизмов сглаживания социального неравенства потребителей медицинской помощи разработана недостаточно как в плане научной рефлексии, так и в практиках прикладных исследований. В то время как в США социологический мониторинг национального прогресса в достижении равенства в области здравоохранения уже давно выведен на уровень институциональной практики [8], в России предпринимаются лишь инициативные социологические замеры общественного мнения о качестве и доступности услуг здравоохранения в целом по стране и отдельных регионах.

Термин «институциональный механизм» разработан и используется преимущественно в экономической теории. Обычно под ним ученые понимают: совокупность организационной и институциональной структур экономического механизма, включающую в себя как отдельные организационные элементы, так и институциональные условия и особенности их взаимодействия, осуществляющую функционирование и достижение целей механизма (состоящих в обеспечении соответствующего экономического процесса) [9]; особую структурную составляющую хозяйственного механизма, обеспечивающую «создание норм и правил, взаимодействие различных хозяйствующих субъектов и агентов с целью реализации их экономических возможностей и стабилизации хозяйственной среды» [10, с. 47]; систему «трансформации неупорядоченных взаимодействий хозяйственных субъектов с целью социального упорядочения и закрепления их функций в соответствии с требованиями традиционно существующих или легитимно установленных обществом институтов» [11, с. 23]. 
Адаптируя вышеприведенные дефиниции к сфере здравоохранения, под институциональным механизмом будем понимать систему согласования и упорядочения интересов различных агентов посредством разработки и установления взаиморазделяемых формальных и неформальных социальных норм в сфере потребления медицинской помощи с последующей их интериоризацией и социальным воспроизводством. Институциональный механизм системы здравоохранения является структурной составляющей экономического механизма. Основными агентами институционального механизма системы здравоохранения являются: государство (включая федеральные, региональные и муниципальные органы управления здравоохранением, федеральный и территориальные фонды обязательного медицинского страхования), персонал медицинских организаций, персонал страховых медицинских организаций, потребители медицинской помощи, работодатели. Используя понятие «агент», мы акцентируем внимание на сознательной активности субъектов здравоохранения, являющихся не просто «функциями в системе», но заинтересованными акторами. К тому же есть и другие не менее значимые «игроки»: фармацевтические корпорации, производители медицинской техники, медицинская реклама в средствах массовой коммуникации.

Здравоохранение в современной России - это не только социальный институт, охраняющий здоровье человека и общества, но и социальное поле пересечения интересов страховых медицинских организаций и медицинских организаций, государства и медицинского сообщества, государства и потребителей, потребителей и медицинских организаций, а также других агентов между собой. Процессы в сфере здравоохранения должны быть объектом социального управления. Социальный институт здравоохранения нуждается в перенастройке отдельных подсистем и механизмов для того, чтобы агенты не только могли достигать своих реальных интересов, но и обеспечивать условно-справедливое распределение дефицитных ресурсов здравоохранения. На сегодняшний день формальные функции и реальные интересы основных агентов в достаточной степени контрадикторны. Анализ основных противоречий представлен в таблице.

Если рассуждать с позиции структурно-функционального анализа в социологии, потребление медицинской помощи рассматривается как система отношений между различными агентами, складывающаяся как в структурах института здравоохранения (прежде всего - в медицинских организациях), так и за их пределами в любой точке социального пространства. Именно поэтому мы используем термин «потребитель», а не «пациент». Вместе с тем осознание потребности в медицинском вмешательстве не всегда сопряжено с объективной его необходимостью или возможностью реализации. Подобный диссонанс вызван разнообразными факторами, среди которых важную роль играет именно разновекторность интересов личности, социальных групп, государства, медицинских корпораций, явно или латентно институционализированных в медицинской культуре социального поля здравоохранения. Так, для государства человек - объект и одновременно субъект решения государственных задач. Следовательно, здоровье/болезнь «определяется государством как способность или неспособность быть трудовым и мобилизационным ресурсом определенного свойства. Государственные институты здравоохранения относят человека к категориям «годного к военной службе», «годного для обучения в вузе», «больного туберкулезом», «психически больного», «инвалида» и т. д.» $[12$, с. 20]. С. Г. Кордонский считает, что немаловажным является то обстоятельство, что «представления о здоровье, которые реализуют в своей практике врачи и фармацевты, определяются корпорациями <...> у кардиологов одно представление о здоровье и соответствующая социальная практика, у дерматологов - другое. Нередки случаи, когда какая-то болезнь становится социальным фактом только потому, что корпорация это пролоббировала» $[12$, с. 20]. Особенно это актуально для формирования программ активного долголетия и благополучного старения, пересмотра сущест- 
вующих подходов к поддержанию и сохранению здоровья пожилых людей [13], т. к. именно старшие возрастные когорты испытывают сравнительно большие потребности в медицинской помощи и чаще других становятся депривированной социальной группой [14]. Немаловажным фактором, способным снизить доступность медицинской помощи, является стигматизация, лишающая уязвимые группы населения со специфическими медицинскими потребностями (психические заболевания, ВИЧ, рак, лепра и пр.) возможности воздействовать на социальные контексты, определяющие их опыт, поведение и действия как пациентов [15].

\section{Таблица. Функции и интересы агентов института здравоохранения в современной России}

Table. Agents' functions and interests of the health care institute in Russia today

\begin{tabular}{|c|c|c|}
\hline Агенты/Agents & $\begin{array}{c}\text { Формальные функции } \\
\text { Formal functions }\end{array}$ & Реальные интересы/Real interests \\
\hline Государство/State & $\begin{array}{l}\text { Обеспечение и регулирование условий } \\
\text { для удовлетворения медицинских по- } \\
\text { требностей общества } \\
\text { Maintenance and regulation of conditions } \\
\text { to meet the health needs of the community }\end{array}$ & $\begin{array}{l}\text { Снижение бюджетной финансовой } \\
\text { нагрузки в сфере здравоохранения } \\
\text { Reducing the budgetary financial } \\
\text { burden in the healthcare sector }\end{array}$ \\
\hline $\begin{array}{l}\text { Медицинские организации } \\
\text { Medical organizations }\end{array}$ & $\begin{array}{l}\text { Лечение, диагностика, профилактика } \\
\text { заболеваний } \\
\text { Treatment, diagnosis, disease prevention }\end{array}$ & $\begin{array}{l}\text { Сохранение монополии на оказа- } \\
\text { ние медицинской помощи, извле- } \\
\text { чение прибыли и защита профес- } \\
\text { сиональной репутации } \\
\text { Maintaining a monopoly on provision } \\
\text { of medical care, making a profit and } \\
\text { protecting professional reputation }\end{array}$ \\
\hline $\begin{array}{l}\text { Страховые медицинские } \\
\text { opганизации } \\
\text { Medical insurance companies }\end{array}$ & $\begin{array}{l}\text { Посредническое финансирование, } \\
\text { организация и экспертиза в сфере } \\
\text { оказания медицинской помощи } \\
\text { Mediation financing, organization and } \\
\text { expertise in the field of medical care }\end{array}$ & $\begin{array}{l}\text { Максимизация прибыли } \\
\text { Profit maximization }\end{array}$ \\
\hline $\begin{array}{l}\text { Потребители медицинской } \\
\text { помощи } \\
\text { Medical care consumers }\end{array}$ & $\begin{array}{l}\text { Выбор медицинской организации, вра- } \\
\text { ча, страховой медицинской организа- } \\
\text { ции, выполнение медицинских предпи- } \\
\text { саний и рекомендаций } \\
\text { Choosing a medical organization, doctor, } \\
\text { medical insurance company, fulfilling } \\
\text { medical prescriptions and recommenda- } \\
\text { tions }\end{array}$ & $\begin{array}{l}\text { Получение своевременной, безо- } \\
\text { пасной и адекватной медицинской } \\
\text { помощи с минимальными времен- } \\
\text { ными и финансовыми издержками } \\
\text { Getting timely, safe and adequate } \\
\text { medical care with minimal time and } \\
\text { financial costs }\end{array}$ \\
\hline $\begin{array}{l}\text { Производители и реализато- } \\
\text { ры фармацевтической и ме- } \\
\text { дико-технической продукции } \\
\text { Manufacturers and distributors } \\
\text { of pharmaceutical and medical- } \\
\text { technical products }\end{array}$ & $\begin{array}{l}\text { Производство и реализация качествен- } \\
\text { ных и эффективных препаратов и меди- } \\
\text { цинских продуктов } \\
\text { Production and realization of high-quality } \\
\text { and effective medicaments and medical } \\
\text { products }\end{array}$ & $\begin{array}{l}\text { Максимизация прибыли } \\
\text { Profit maximization }\end{array}$ \\
\hline $\begin{array}{l}\text { Медицинская Реклама } \\
\text { Medical advertising }\end{array}$ & $\begin{array}{l}\text { Информирование потребителей о воз- } \\
\text { можностях получения медицинских } \\
\text { услуг } \\
\text { Informing consumers about the possibili- } \\
\text { ties of obtaining medical services }\end{array}$ & $\begin{array}{l}\text { Максимизация прибыли } \\
\text { Profit maximization }\end{array}$ \\
\hline Работодатели/Employers & $\begin{array}{l}\text { Уплата страховых взносов, организация } \\
\text { медицинских осмотров, инициативная } \\
\text { медиация в программах добровольного } \\
\text { медицинского страхования } \\
\text { Payment of insurance premiums, the organ- } \\
\text { ization of medical examinations, proactive } \\
\text { mediation in the voluntary health insurance } \\
\text { programs }\end{array}$ & $\begin{array}{l}\text { Повышение трудоспособности } \\
\text { работников при минимальных } \\
\text { затратах } \\
\text { Increasing working capacity with a } \\
\text { minimal cost }\end{array}$ \\
\hline
\end{tabular}


Государство заинтересовано в сокращении степени финансового и организационного участия в здравоохранении (именно с этим связано появление и динамичное развитие института обязательного медицинского страхования в современной России), в то время как медицинские организации стремятся к расширению влияния и укреплению авторитета в обществе. Для медиков, страховщиков, фарминдустрии важно наличие пациентов и финансовых потоков, которые за ними идут из различных источников: фондов обязательного и добровольного медицинского страхования, субсидий из государственного бюджета, прямых платежей формального и неофициального характера. Что касается интересов государства и общества в сфере здравоохранения, то они в целом согласуются, однако население до сих пор ожидает поддержки и участия государства в социальной сфере, в то время как государство планомерно снижает планку гарантированной бесплатной медицинской помощи и постепенно ослабляет механизмы контроля и надзора, повышая степень персональной ответственности человека за свое здоровье и благополучие, а организационно-финансовые функции в сфере здравоохранения делегирует другим агентам.

Медицинские организации, в свою очередь, находятся в зависимости от страховых медицинских организаций, поскольку именно они осуществляют финансирование по факту оказанной медицинской помощи в российской системе обязательного медицинского страхования. Главной целью страховых медицинских организаций являются извлечение прибыли и минимизация объема финансирования услуг, оказываемых медицинскими организациями по территориальной программе обязательного медицинского страхования. Медицинские организации, напротив, мотивированы на максимальную компенсацию затрат на оказание медицинской помощи. В этом столкновении интересов проигрывают обычно пациенты, для которых полис медицинского страхования, выдаваемый страховыми медицинскими организациями в регионе - не более чем «пропускной билет» к врачу, ибо медицинские организации вынуждены возводить организационные барьеры для регулирования потока пациентов и избегать штрафных санкций за необоснованно завышенные объемы предоставленной медицинской помощи по программе госгарантий. Потребителям остается преодолевать либо организационные барьеры, либо личные финансовые, оплачивая медицинскую помощь напрямую по договорам и неофициально, или опосредованно через добровольное медицинское страхование.

До сих пор остро стоит проблема влияния мотивации врачей на формирование доступности медицинской помощи. Ученые Высшей школы экономики А.Е. Чирикова и С.В. Шишкин по результатам глубинных интервью с врачами и руководителями медицинских организаций Москвы и одного из регионов европейской части России $(N=36)$ выявили разнонаправленный характер влияния эффективного контракта на мотивацию врачей. Исследование показало, что материальные и нематериальные мотивы труда врачей - «относительно независимы и, как правило, дополняют друг друга в их сознании. В подавляющем большинстве случаев реальная мотивация включает в себя одновременно и материальные, и нематериальные переменные, а потому работа только с одной из этих групп не может дать полностью удовлетворяющие результаты» [16, с. 39]. Так, респонденты нередко сообщали социологам о снижении мотивации к труду по причине отсутствия необходимых профессиональных компетенций, условий реализации медицинской деятельности, прогрессивных лекарств в медицинских учреждениях. И это несмотря на ощутимые стимулирующие надбавки, предусмотренные эффективными контрактами и общий рост оплаты труда врачей. Дополнительным фактором, который обесценивает рост материального стимулирования врачей, исследователи называют неформальные платежи, перекрывающие порою все официальные надбавки. 
Интересы государства и производителей, реализаторов фармацевтической и медико-технической продукции также совпадают, если не считать того обстоятельства, что любой предприниматель от медицины стремится максимизировать свою прибыль, увеличивая объемы продаж как отечественных, так и импортных лекарств, как действенной, так и бесполезной продукции, в общем всего, что продается и покупается. Рост цен на медикаменты и медицинские услуги наносит удар в первую очередь по имиджу государства и его уполномоченных организаций и представителей. Государство предоставляет существенную свободу действий фармацевтическим корпорациям и производителям медицинской техники и оборудования, т. к. они являются крупными налогоплательщиками. Вдобавок, по мнению экспертов, сегодня крайне высока зависимость отечественной фармацевтической отрасли от импорта, официальные данные по импортозамещению лекарственной продукции сильно преувеличены, а «объективная возможность медикаментозных санкций в отношении России ставит физическую доступность препаратов для россиян под угрозу, а вопрос об автономии отечественной фармацевтической отрасли от стран Запада остается дискуссионным» [17].

Вот и получается, что конфликт интересов различного рода агентов вносит коррективы в стабильное функционирование системы здравоохранения, интегральной функцией которой является сохранение и укрепление здоровья общества и отдельного человека. Нельзя в полной мере утверждать, что обозначенные противоречия имеют решающее значение для социальной дифференциации потребления медицинской помощи, однако бессмысленно принимать какие-то усилия в сглаживании неравенства пациентов и предпациентов, если явные и латентные функции в институциональном пространстве здравоохранения настолько расходятся. Следовательно, необходим пересмотр самой парадигмы здравоохранения и медицины в современной России с последующим социальным конструированием новой идеологии здоровья и здравоохранения.

В качестве идейно-теоретической основы стратегии социальной политики по сглаживаниию неравенства потребителей медицинской помощи может быть положена концепция трансформационной активности Т.И. Заславской. Трансформационная активность - это «совокупность таких социально-инновативных действий, которые, будучи относительно рациональным ответом акторов на вызываемое реформами изменение условий жизнедеятельности, существенно меняют базовые социальные практики» [18, с. 221]. В результате существенных изменений социально-экономического уклада, характера межличностных и межгрупповых взаимодействий в обществе, трансформируется и институциональная среда. Как следствие, по мнению Т.И. Заславской, «поведение социальных акторов, независимо от их типов и статусов, реализуется в рамках достаточно жестких структурных ограничений, роль которых в трансформации общественных практик не меньше, чем инициативных действий свободных акторов» $[18$, c. 221]. Действительно, реакция общества на социальные изменения является в большей степени осознанной, а поступки рациональными. При выборе стратегий самосохранительного поведения, в том числе и поведения на рынке медицинских услуг, существенное влияние оказывают институциональные системы, социальная структура, социально-демографические и статусные характеристики общества, являющиеся идентификаторами места потребителя медицинской помощи в общественной жизни.

Опираясь на типологию институциональных механизмов О.В. Иншакова и Н.Н. Лебедевой [11], можно выделить три базовых институциональных механизма сглаживания социального неравенства потребителей медицинской помощи: регламентирующий, интериоризирующий, воспроизводящий. Первый направлен на установление однозначных норм, обеспечивающих эффективное взаимодействие всех агентов, 
прежде всего потребителей, медицинских организаций и страховщиков. Второй, интериоризирующий тип, призван герметизировать новые нормы в сознании агентов посредством формирования идеологии здоровья и здравоохранения. Третий механизм должен обеспечить воспроизводство культуры потребления медицинской помощи как неотъемлемой подсистемы культуры здоровья - системы ценностей, идей и норм различных социальных групп и общества по отношению к собственному здоровью. Эффективное функционирование обозначенных механизмов возможно только при условии социального диалога всех заинтересованных агентов и только при условии совместных усилий государства и социальных институтов здравоохранения, образования и семьи.

Активизировать регламентирующий, интериоризирующий и воспроизводящий механизмы под силу только государству. Для этого требуется соблюдение ряда институциональных условий, а именно: детализации сфер ответственности агентов; преемственности процесса лечения и наблюдения пациентов; сокращения непосредственных платежей потребителей за медицинскую помощь; перераспределения кадровых, технологических, финансовых ресурсов здравоохранения внутри регионов; конкретизации государственных гарантий оказания медицинской помощи; социологического мониторинга потребления медицинской помощи. Говоря о социологическом мониторинге неравенства и несправедливости в здравоохранении, зарубежные авторы подчеркивают важность информирования широкого круга заинтересованных сторон о проводимых в этой области исследованиях для лучшего выбора мер социальной политики и совершенствования аналитических методов [8].

Как уже отмечалось, одним из главных ограничений позитивизации потребления медицинской помощи и создания доступной среды здравоохранения является низкий адаптационный потенциал социальных моделей потребления медицинской помощи. Общество ни ментально, ни инструментально не подготовлено к резкому увеличению личной ответственности в сфере здравоохранения [19]. Хотя необходимость установления нового разделения ответственности, по мнению А.Е. Чириковой и С.В. Шишкина, в том числе экономической, между врачами, пациентами, государством за состояние здоровья и проведение лечения назрела уже давно. Нарастание напряженности в отношениях врачей и пациентов, формирование общественного запроса на новую, партнерскую модель их отношений, укоренение практик неформальной оплаты медицинской помощи» интенсифицируют трансформационный кризис российского здравоохранения [20, с. 177]. За годы социальных экспериментов в сфере здравоохранения существенно возросло институциональное недоверие к здравоохранению и его организациям. Значительным препятствием является дефицит бюджетных средств, и как следствие, выполнение социальных обязательств российского государства перед обществом затруднено. Государственно-частное партнерство в сфере здравоохранения развито пока слабо, поскольку сопряжено с высокими рисками как для бизнеса, так и для государства.

Таким образом, в ближайшие годы, скорее всего, система здравоохранения будет развиваться по инерционному сценарию с сосуществованием номинальных государственных гарантий оказания медицинской помощи и неуклонным ростом официальных и неформальных платежей населения. Доступность медицинской помощи в лучшем случае останется на прежнем уровне.

Существенное значение приобретает дифференцирующая роль медицинского выбора пациента. В методологическом и практическом плане интерес представляют результаты качественно-количественного социологического исследования, предпринятого научным коллективом Самарского национального исследовательского университета 
им. С.П. Королева [14]. Ученые пришли к выводу о том, что на этапе так называемого «дебюта болезни» (т. е. манифестации первых симптомов недуга) на принятие решения оказывает линейка таких факторов, как (\% от общего числа опрошенных, $N=510)$ : 1) «финансовая доступность» $(79 \%)$ и «культурное знание» $(75 \%) ; 2)$ «боль и другие интенсивные симптомы» (49 \%) и «отношение к медицинским институциям» (41\%); $3)$ «привычное, рутинное поведение» (29 \%). Например, среди респондентов, предпочитавших обращение к платных услугам при возникновении медицинской потребности, назывались следующие мотивы: «хорошая организация процесса медицинской помощи и качественное лечение», «индивидуальный подход к лечению», «знакомый врач», «высокая квалификация врачей», «благожелательное отношение к пациенту», «отсутствие узкого специалиста в поликлинике», «географическая доступность» $[14$, с. 86]. Разумно предположить, что эти мотивы в известной степени отражают изъяны здравоохранения, типичные для любого региона и являются социально-психологическими факторами социального расслоения потребителей медицинской помощи, поскольку связаны с общим восприятием ситуации в здравоохранении, ожиданиями и стереотипами.

Для того чтобы россияне могли иметь высокий уровень качества жизни, важно целенаправленно управлять общественным здоровьем, поскольку «достоинства и недостатки среды, создаваемой властью, являются своеобразными катализаторами, ускоряющими или замедляющими человеческое развитие» [21, с. 140].

Доступность медицинской помощи ограничивается, с одной стороны, неэффективной государственной политикой в сфере здравоохранения [22, 23]. Трансформация социалистической системы здравоохранения в бюджетно-страховую привела к большим проблемам и противоречиям, главными из которых являются тотальный дефицит финансовых ресурсов в общественных фондах и медицинских организациях, бюрократизация управления отраслью. Все это снижает мотивацию всех агентов к повышению доступности медицинской помощи. Агентами, которые выигрывают на неопределенности и хроническом кризисе здравоохранения, являются разве что страховые медицинские организации, фармацевтические компании, производители и реализаторы медицинских препаратов и техники, представители рекламных агентств, продвигающие бренды клиник, фармацевтической и медико-технической продукции. С другой стороны, социальные модели потребления медицинской помощи недостаточно адаптированы к неолиберальным преобразованиям в области здравоохранения, да и российскому человеку нет дела до организационной модели здравоохранения, для него существует «платная» и «бесплатная» медицинская помощь. Причем бесплатная медицинская помощь в общественном сознании особо и не разделяется на оплачиваемую официально и неофициально.

Зарубежные авторы отмечают, что их системы всеобщего медицинского страхования также далеки от идеала. Так, по данным социологического опроса, проведенного в Австралии $(N=4574$ чел. старше 50 лет), несмотря на всеобщее медицинское страхование и систему социальной защиты медицинских и фармацевтических взносов, 4 \% опрошенных австралийцев с хроническими заболеваниями в течение трех месяцев до проведения опроса были не в состоянии позволить себе прямые расходы на медицинское обслуживание (речь в исследовании шла о медицинских консультациях и тестах, лекарственном обеспечении, стоматологических назначениях, физиотерапии, ортопедии и трансфере к медицинским организациям) [24]. Для сравнения, по данным выборочного опроса, проведенного с участием автора в 2017 г. на Юге России $(N=3900$ чел., проживающих в Ростовской области, Краснодарском крае, Ставропольском крае, 
Республике Адыгея, Кабардино-Балкарской республике, Республике Крым), 44 \% респондентов в течение года были вынуждены частично или полностью отказываться от лечения или диагностики в медицинских организациях из-за отсутствия финансовой возможности. В Кабардино-Балкарской республике и Республике Адыгея количество респондентов, не имевших возможность оплачивать медицинскую помощь, более половины (53,2 и 57,4\% соответственно) [25].

На Западе активно исследуются проблемы неравенства в доступе к медицинской помощи этнических меньшинств и проблемы их стигматизации в поле клинической медицины [15]. Британские ученые по итогам исследования более 10 тыс. больных шизофренией пришли к выводу о том, темнокожие пациенты и люди с азиатской внешностью по сравнению с белыми пациентами потребляют сравнительно меньший объем медикаментозной, психологической терапии, а также реже включены в планы медицинского ухода. По мнению социологов, это обусловлено латентной политикой дискриминации по этническому признаку [26]. Поэтому для измерения неравенства в здравоохранении методологически необходимо различать «доступ к медицинским услугам» и «использование медицинских услуг» [5, с. 17]. По оценкам специалистов Высшей школы экономики, в нашей стране до сих пор отсутствуют система государственных гарантий сроков ожидания, прозрачность в организации очереди на плановую медицинскую помощь и порядок ее прохождения, мониторинг сроков ожидания, фактические показатели ожидания по отдельным видам медицинской помощи [27]. Следовательно, доступность медицинской помощи в широком понимании включает не только процесс вхождения человека в систему медицинского обеспечения и этапы передвижения пациента с одного уровня оказания медицинской помощи на другой, но и конечный результат обращения к врачам.

Согласно данным представителей Социологического института - филиала Федерального научно-исследовательского социологического центра РАН, в менее развитой части Европы, включающей и Россию, где нижним слоям не приходится рассчитывать на серьезную помощь со стороны государства, особую роль играют психологические ресурсы личности, выступающие «медиатором социального структурирования здоровья〉 $[28$, с. 44$]$. Можно предположить, что это утверждение справедливо и в отношении «приобретения» доступа к медицинской помощи, зависящего во многом от психологических ресурсов личности (веры и институционального доверия, воли, характера), объема и структуры ее социального и культурного капиталов. На взгляд О.А. Полюшкевич, «личность человека или характеристика группы людей выступает своего рода маркером, по которому мы можем судить о восприятии боли и болезни как социальных категорий (при этом они всегда остаются индивидуально-личностными формами переживания)» $[29$, с. 147$]$.

Подведем итоги. Как мы выяснили, в настоящее время в современной научной литературе актуализируется вопрос о необходимости проведения как фундаментальных междисциплинарных, так и специальных, узконаправленных прикладных исследований, направленных на объяснение и прогнозирование перспектив сглаживания социального неравенства пациентов и «предпациентов». Большинство научных исследований разворачивается вокруг таких проблемно-предметных полей, как влияние социально-экономических перемен на здоровье населения, векторы самосохранительного поведения, роль и потенциал формирования здорового образа жизни в обществе, медикосоциальные аспекты конструирования культуры здоровья. Вышеперечисленные факторы формируют условия и институциональное пространство взаимодействия различных агентов в контексте здоровьесбережения, однако именно характер взаимодействий, со- 
циальные особенности и характер внешней среды являются для человека зачастую определяющими при ответе на вопрос о степени удовлетворенности своим здоровьем. Ведь речь идет не просто об устранении психофизических недугов и снижении степени рискогенности окружающей среды по отношению к обществу, а о социальном поведении людей в сфере общественного здоровья и роли базовых социальных институтов в процессе воспроизводства практик самосохранительной либо самодеструктивной активности. Данная тема приобретает особую значимость в контексте трансформации социального, экономического, политического и правового устройства российского социума и отдельных регионов, т. к. и негативные и позитивные тенденции в здравоохранении, как правило, носят системный характер и хоть появляются локально, но представляют собой результат фундаментальных изменений в социальной структуре общества.

В условиях нестабильного социально-экономического развития российского общества революционные перемены в здравоохранении рискованны и нецелесообразны. Однако это не исключает возможности экспериментальной перенастройки социальных отношений между агентами без форматирования основополагающих принципов системы в интересах выравнивания социальных различий в доступе к медицинской помощи [5, с. 171]. Учитывая дефицитарность финансирования здравоохранения, обеспечить постепенное повышение доступности медицинской помощи и, как следствие, сократить социальное неравенство ее потребителей можно посредством «мягкой силы» и методологии «маленьких шагов». Подобная политика должна быть ориентирована на конкретизацию гарантий бесплатной медицинской помощи на макро- и микроуровнях; установление верхней границы прямых официальных соплатежей для социально уязвимых групп населения; проработку механизма прогрессивной шкалы отчисления индивидуальных страховых взносов в фонд обязательного медицинского страхования; пересмотр целесообразности участия коммерческих медицинских организаций в программах обязательного медицинского страхования; расширение зоны индивидуальных и коллективных программ добровольного медицинского страхования с соответствующим нормативно-правовым обеспечением; ограничение либо запрет рекламы лекарственных и иных препаратов в средствах массовой коммуникации; установление в городских поликлиниках лимита предварительных записей к узким специалистам. Вышеперечисленные меры обязательно должны обеспечиваться информационной социализацией пациентов [30], социологическим мониторингом потребностей населения в медицинской помощи и публичными обсуждениями экспертным сообществом вопроса о целесообразности развития института обязательного медицинского страхования России в том виде, в котором он существует на текущий момент.

Статья подготовлена в рамках реализации гранта Президента РФ № МК-4089.2018.6 «Социальная сущность и механизмы дифференциации потребления медищинской помощи в российском обществе» (Соглашение № 075-15-2019-1051).

\section{СПИСОК ЛИТЕРАТУРЫ}

1. Braveman P. What are health disparities and health equity? We need to be clear // Public Health Reports. - 2014. V. 129 (Suppl. 2). - P. 5-8. DOI: 10.1177/00333549141291S203. URL: https://ru.scribd.com/document/ 354962960/What-Are-Health-Disparities-and-Health-Equity-We-Need-to-Be-Clear (дата обращения 10.08.2019).

2. Двадцать пять лет социальных трансформаций в оценках и суждениях россиян: опыт социологического анализа / под ред. М.К. Горшкова, В.В. Петухова. - М.: Весь Мир, 2018. - 384 с.

3. Мареева С.В., Тихонова Н.Е. Бедность и социальные неравенства в России в общественном сознании // Мир России: Социология, этнология. - 2016. - № 2. - С. 37-67. 
4. Вялых Н.А. Механизмы дифференциации потребления медицинской помощи в России: методологический поворот в современных социологических исследованиях // Вестник Томского государственного университета. Философия. Социология. Политология. - 2018. - № 45. - С. 122-138.

5. Pulok M.H. Horizontal equity in the Australian healthcare system: Exploring the unknowns and updating the knowns. - Australia: University of Technology Sydney (UTS), 2019. - 221 p. URL: https://www.researchgate.net/project/Horizontal-equity-in-the-Australian-health-care-system-Exploring-theunknowns-and-updating-the-knowns (дата обращения 10.08.2019).

6. Вялых Н.А. Социальные факторы дифференциации потребления медицинской помощи: объективизм VS субъективизм // Вестник науки Сибири. - 2018. - № 4. - С. 158-170.

7. Braveman P. What is health equity: and how does a life-course approach take us further toward it? // Maternal and child health journal. - 2014. - V. 18. - Iss. 2. - P. 366-372.

8. Measurement of Health Disparities, Health Inequities, and Social Determinants of Health to Support the Advancement of Health Equity / A. Penman-Aguilar, M. Talih, D. Huang, R. Moonesinghe, K. Bouye, G. Beckles // Journal of Public Health Management and Practice. - 2016. - V. 22. - P. 33-42.

9. Ященко С.О., Никифорова М.Е. Сущность институционального механизма как составляющей экономической системы // Известия Дальневосточного федерального университета. Экономика и управление. - 2014. - № 1 (69). - С. 11-19.

10. Истомин С.В. Сравнительный анализ институционального и хозяйственного механизмов в трансформируемой экономике // Вестник Челябинского государственного университета. Экономика. 2010. - № 27 (208). - Вып. 29. - С. 47-51.

11. Иншаков О.В., Лебедева Н.Н. Типология и классификация институциональных механизмов // Экономика развития региона: проблемы, поиски, перспективы: сборник научных трудов. - Волгоград: Изд-во ВолГУ, 2002. - С. 23-37.

12. Система поддержания здоровья в современной России: сборник статей и материалов полевых исследований / под ред. И.В. Кошкаровой. - М.: Страна О3, 2012. - 400 с.

13. Аникина Е.А., Иванкина Л.И. Отношение к старости как фактор благополучного старения // Векторы благополучия: экономика и социум. - 2019. - № 2 (33). - С. 63-71.

14. Лехциер В.Л., Готлиб А.С., Финкельштейн И.Е. Медицинский выбор хронических больных в крупном российском городе: ситуации, практики, факторы // Социологический журнал. - 2019. - Т. 25. № 2. - C. 78-98.

15. The Health Stigma and Discrimination Framework: a global, crosscutting framework to inform research, intervention development, and policy on health-related stigmas / A.L. Stangl, V.A. Earnshaw, C.H. Logie, W. Brakel, L.C. Simbayi // BMC Medicine. - 2019. - V. 17 (31). - URL: https://bmcmedicine.biomedcentral.com/articles/10.1186/s12916-019-1271-3 (дата обращения 09.08.2019).

16. Чирикова А.Е., Шишкин С.В. Эффективный контракт и мотивация: способны ли реформы улучшить работу российских врачей? // Социологические исследования. - 2019. - № 5. - С. 36-44.

17. Фадеева Е.В. Доступность лекарственных препаратов в условиях медикаментозного эмбарго: по материалам исследований // Социологические исследования. - 2019. - № 4. - С. 77-85.

18. Заславская Т.И. Современное российское общество: социальный механизм трансформации. - М.: Дело, 2004. - 400 c.

19. Lubsky A., Vyalykh N. Modal Models of Social Behavior of Medical Care Consumers in the Russian Society // Journal of Advanced Research in Law and Economics. - 2017. - V. 8. - Iss. 5 (27). - P. 1185-1192.

20. Чирикова А.Е., Шишкин С.В. Взаимодействие врачей и пациентов в современной России: векторы изменений // Мир России: Социология, этнология. - 2014. - Т. 23. - № 2. - С. 154-182.

21. Качество жизни как критерий социального управления / С.А. Ильиных, М.В. Удальцова, Н.Г. Сухорукова, Е.В. Наумова // Векторы благополучия: экономика и социум. - 2019. - № 1 (32). - 133-143.

22. Braveman P., Gottlieb L. The social determinants of health: it's time to consider the causes of the causes // Public Health Rep. - 2014. - № 129 (suppl. 2). - P. 19-31.

23. The political origins of health inequity: prospects for change / O. Ottersen, J. Dasgupta, C. Blouin, et al. // Lancet. - 2014. - № 383 (9917). - P. 630-667.

24. Affordability of out-of-pocket health care expenses among older Australians / A. Carpenter, M.I. Mofizul, L. Yen, I. McRae // Health Policy. - 2015. - V. 119. - Iss. 7. - P. 907-914.

25. Ментальные программы и модальные модели социального поведения на Юге России: монография / отв. ред. А.В. Лубский. - М.: Социально-гуманитарные знания, 2017. - 396 с.

26. Das-Munshi J., Bhugra D., Crawford M.J. Ethnic minority inequalities in access to treatments for schizophrenia and schizoaffective disorders: findings from a nationally representative cross-sectional study // 
BMC Medicine. - 2018. - № 16 (55). URL: https://doi.org/10.1186/s12916-018-1035-5 (дата обращения 09.08.2019).

27. Сроки ожидания медицинской помощи: зарубежный опыт и российская практика // Доклады к ХХ Апрельской международной научной конференции по проблемам развития экономики и общества, Москва, 9-12 апр. 2019 г. / рук. авт. кол. И.М. Шейман, С.В. Шишкин. - М.: ИД Высшей школы экономики, 2019. - 87 с.

28. Русинова Н.Л., Сафронов В.В. Психологические медиаторы социальных неравенств в здоровье: «уверенность в себе» в Европе и России // Социологический журнал. - 2018. - Т. 24. - № 4. - С. $30-53$.

29. Полюшкевич О.А. Боль и болезнь как социальные явления // Социология. - 2019. - № 1. - С. $147-153$.

30. Шишкина Е.В. Инфосоциализация пациентов в условиях информатизации здравоохранения (по материалам социологических исследований) // Вестник Адыгейского государственного университета. Серия 1: Регионоведение: философия, история, социология, юриспруденция, политология, культурология. - 2013. - № 1 (113). - С. 165-169.

Поступила 12.08.2019 2. 


\title{
INSTITUTIONAL CONDITIONS AND MECHANISMS OF ANTIALIASING SOCIAL INEQUALITY OF CONSUMERS OF MEDICAL CARE IN RUSSIAN SOCIETY
}

\author{
Nikita A. Vyalykh, \\ sociology4.1@yandex.ru \\ Southern Federal University, \\ 160, Pushkinsky Avenue, Rostov-on-Don, 344006, Russia.
}

Nikita A. Vyalykh, Cand. Sc., associate professor, Southern Federal University.

The article deals with the practical approaches to reducing the degree of medical care consumption differentiation in modern Russian society. The relevance of the research is caused by the necessity to construct an accessible and effectiveness healthcare field in Russia. The novelty of the work is expressed in indication of contradiction between explicit functions and real interests of agents in the healthcare system. A special attention is given to the consequences of government participation reduction in the healthcare. It is argued that, in general, the government and consumers' interests in the field of medical support are the same. However, society still expects support and care from government, but the government is gradually reducing its participation. The author focuses on theoretical and methodological backgrounds of sociological understanding of social differences in medical care consumption and defines the measures of actors' behavioral strategies positivisation in the context of transformation of the healthcare institution in Russia today. Antialiasing of health care consumption differentiation depends on operation of regulatory, interiorizationing and reproducing institutional mechanisms. The article shows that institutional mechanism is a system of coordination and streamlining of the interests of different agents through the development and establishment of formal and informal social norms in the healthcare sphere with subsequent interiorization and social reproduction. Special attention is given to the analysis of behavioral and structural dimensions of inequality in access to medical care. It is argued that the strengthening of state control is a necessary step in the sphere of healthcare, but motivation to modernization of the healthcare system in the budget and insurance model is extremely weak. Finally, the author comes to the conclusion on possibility of antialiasing the social inequality of medical care consumers by means of specification guarantees of free medical care and responsibility of agents, reduction of patients' direct payments, integrating of treatment process, social dialogue and infosocialization of agents.

Key words: Social differentiation, medical care consumption, medical care accessibility, Russian healthcare, agents, transformation, institutional mechanisms.

The paper was written within implementation of the grant of the RF President no. MK-4089.2018.6 «Social substance and mechanisms of differentiation of consuming medical care in Russia» (Agreement no. 075-15-2019-1051).

\section{REFERENCES}

1. Braveman P. What are health disparities and health equity? We need to be clear. Public Health Reports, 2014, vol. 129 (Suppl. 2), pp. 5-8. DOI: 10.1177/00333549141291S203. Available at: https://ru.scribd.com/document/354962960/What-Are-Health-Disparities-and-Health-Equity-We-Need-toBe-Clear (accessed 10 August 2019).

2. Dvadtsat pyat let sotsialnykh transformatsiy v otsenkakh i suzhdeniyakh rossiyan: opyt sotsiologicheskogo analiza [Twenty-five years of social transformations in the estimates and judgments of the Russians: the experience of sociological analysis]. Eds. M.K. Gorshkov, V.V. Petukhov. Moscow, Ves Mir Publ., 2018. $384 \mathrm{p}$.

3. Mareeva S.V., Tikhonova N.E. Poverty and social inequalities in Russia in the public consciousness. Universe of Russia: Sociology, ethnology, 2016, no. 2, pp. 37-67. In Rus. 
4. Vyalykh N.A. Differentiation mechanisms of medical care consumption in Russia: a methodological turn in contemporary sociological research. Tomsk State University Bulletin. Philosophy. Sociology. Political science, 2018, no. 45, pp. 122-138. In Rus.

5. Pulok M.H. Horizontal equity in the Australian healthcare system: Exploring the unknowns and updating the knowns. Australia, University of Technology Sydney (UTS), 2019. 221 p. Available at: https://www.researchgate.net/project/Horizontal-equity-in-the-Australian-health-care-system-Exploring-theunknowns-and-updating-the-knowns (accessed 10.08.2019).

6. Vyalykh N.A. Social differentiation factors of medical care consumption: objectivism VS subjectivism. Siberian Journal of Science, 2018, no. 4, pp. 158-170. In Rus.

7. Braveman P. What is health equity: and how does a life-course approach take us further toward it? Maternal and Child Health Journal, 2014, vol. 18, Iss. 2, pp. 366-372.

8. Penman-Aguilar A., Talih M., Huang D., Moonesinghe R., Bouye K., Beckles G. Measurement of Health Disparities, Health Inequities, and Social Determinants of Health to Support the Advancement of Health Equity. Journal of Public Health Management and Practice, 2016, vol. 22, pp. 33-42.

9. Yashchenko S.O., Nikiforova M.E. The Essence of the institutional mechanism as a component of the economic system. The bulletin of the Far Eastern Federal University. Economics and Managemen. 2014, no. 4, pp. 11-19. In Rus.

10. Istomin S.V. Comparative analysis of institutional and economic mechanisms in the transformed economy. Bulletin of Chelyabinsk state University, 2010, no. 27 (208), Iss. 29, pp. 47-51. In Rus.

11. Inshakov O.V., Lebedeva H.H. Tipologiya i klassifikatsiya institutsionalnykh mekhanizmov [Typology and classification of institutional mechanisms]. Ekonomika razvitiya regiona: problemy, poiski, perspektivy: Yezhegodnik - sbornik nauchnykh trudov [Regional development Economics: problems, searches, prospects: Yearbook - collection of scientific works]. Volgograd, Publishing house VolSU, 2002. pp. 23 -37.

12. Sistema podderzhaniya zdorovya v sovremennoy Rossii: sbornik statey i materialov polevykh issledovaniy [Health maintenance system in modern Russia: collection of articles and materials of field research]. Ed. by I.V. Koshkarova. Moscow, Strana Oz Publ., 2012. 400 p.

13. Anikina E.A., Ivankina L.I. Attitude toward age as a factor of safe ageing process. Journal of Wellbeing Technologies, 2019, no. 2 (33), pp. 63-71. In Rus.

14. Lekhtsier V.L., Gotlib A.S., Finkelshteyn I.E. Medical choice of chronic patients in a large Russian city: Situations, practices, factors. Sociological Journal, 2019, vol. 25, no. 2, pp. 78-98. In Rus.

15. Stangl A.L., Earnshaw V.A., Logie C.H., Brakel W., Simbayi L.C. The Health Stigma and Discrimination Framework: a global, crosscutting framework to inform research, intervention development, and policy on health-related stigmas. BMC Medicine, 2019, vol. 17 (31). Available at: https://bmcmedicine.biomedcentral.com/articles/10.1186/s12916-019-1271-3 (accessed 9 August 2019).

16. Chirikova A.E., Shishkin S.V. Effective contract and motivation: can reforms improve the work of the Russian doctors? Sociological Studies, 2019, no. 5, pp. 36-44. In Rus.

17. Fadeeva E.V. Availability of medicines under conditions of medicinal embargo. Sociological Studies, 2019, no. 4, pp. 77-85. In Rus.

18. Zaslavskaya T.I. Sovremennoe rossiyskoe obshchestvo: sotsialny mekhanizm transformatsii [Modern Russian society: social mechanism of transformation]. Moscow, Delo Publ., 2004. 400 p.

19. Lubsky A., Vyalykh N. Modal Models of Social Behavior of Medical Care Consumers in the Russian Society. Journal of Advanced Research in Law and Economics, 2017, vol. 8, Iss. 5 (27), pp. 1185-1192.

20. Chirikova A.E., Shishkin S.V. Interaction of doctors and patients in modern Russia: vectors of changes. Universe of Russia: Sociology, ethnology, 2014, vol. 23, no. 2, pp. 154-182. In Rus.

21. Ilinykh S.A., Udaltsova M.V., Sukhorukova N.G., Naumova E.V. Quality of life as a criterion of social management. Journal of Wellbeing Technologies, 2019, no. 1 (32), pp. 133-143. In Rus.

22. Braveman P., Gottlieb L. The social determinants of health: it's time to consider the causes of the causes. Public Health Rep, 2014, no. 129 (suppl. 2), pp. 19-31.

23. Ottersen O., Dasgupta J, Blouin C. The political origins of health inequity: prospects for change. Lancet, 2014, no. 383 (9917), pp. 630-667.

24. Carpenter A., Mofizul M.I., Yen L., McRae I. Affordability of out-of-pocket health care expenses among older Australians. Health Policy, 2015, vol. 119, Iss. 7, pp. 907-914.

25. Mentalnye programmy i modalnye modeli sotsialnogo povedeniya na Yuge Rossii: monografiya [Mental programs and modal models of social behavior in the South of Russia: monography]. Ed. by A.V. Lubsky. Moscow, Socialno-gumanitarnye znaniya Publ., 2017. 396 p.

26. Das-Munshi J., Bhugra D., Crawford M.J. Ethnic minority inequalities in access to treatments for schizophrenia and schizoaffective disorders: findings from a nationally representative cross-sectional study. BMC Medicine, 2018, no. 16 (55). Available at: https://doi.org/10.1186/s12916-018-1035-5 (accessed 9 August 2019). 
27. Sroki ozhidaniya meditsinskoy pomoshchi: zarubezhny opyt i rossiyskaya praktika [Terms of waiting for medical care: foreign experience and Russian practice]. Doklady $k$ XX Aprelskoy mezhdunarodnoy nauchnoy konferentsii po problemam razvitiya ekonomiki $i$ obshchestva [Reports to the XX April International Scientific Conference on the Problems of Economic and Social Development]. Moscow, 9-12 April 2019. Eds. I.M. Sheyman, S.V. Shishkin. Moscow, Higher School of Economics Publ., 2019. 87 p.

28. Rusinova N.L., Safronov V.V. The Psychological mediators of social inequalities in health: self-efficacy in Europe and Russia. Sociological Journal, 2018, vol. 24, no. 4, pp. 30-53. In Rus.

29. Polyushkevich O.A. Pain and illness as social phenomena. Sociology, 2019, no. 1, pp. 147-153. In Rus.

30. Shishkina E.V. Infosocialization of patients in the context of healthcare informatization (based on sociological research). Bulletin of the Adygea State University. Series 1: Regional studies: philosophy, history, sociology, jurisprudence, political science, cultural science, 2013, no. 1 (113), pp 165-169. In Rus.

Received: 12 August 2019. 